\title{
A Hypoglycemia-inducing Giant Borderline Phyllodes Tumor Secreting High-molecular-weight Insulin-Like Growth Factor II: Immunohistochemistry and a Western Blot Analysis
}

\author{
Masahiro Hikichi ${ }^{1}$, Yuka Kiriyama ${ }^{2}$, Takanori Hayashi ${ }^{3}$, Kaori Ushimado ${ }^{1}$, \\ Naomi Kobayashi ${ }^{1}$, Makoto Urano ${ }^{2}$, Makoto Kuroda ${ }^{2}$ and Toshiaki Utsumi ${ }^{1}$
}

\begin{abstract}
:
A 50-year-old woman with a large right breast mass was emergently hospitalized for generalized weakness and fatigue. A histological examination of tumor biopsy specimens revealed a phyllodes tumor (PT). She suddenly lost consciousness due to severe hypoglycemia. Non-islet cell tumor hypoglycemia (NICTH) due to the PT was suspected. The tumor was emergently resected. A histological examination revealed a borderline PT. The patient recovered from the hypoglycemic episode. High-molecular-weight insulin-like growth factor II was detected in serum that had been collected preoperatively and in the tumor tissue, but not in serum that had been collected postoperatively. We herein present a case of a borderline PT with NICTH.
\end{abstract}

Key words: non-islet cell tumor hypoglycemia, phyllodes tumor, insulin-like growth factor II, immunohistochemistry, Western blotting

(Intern Med 57: 237-241, 2018)

(DOI: 10.2169/internalmedicine.9287-17)

\section{Introduction}

Hypoglycemia represents a common endocrine emergency that is often associated with diabetes treatment or endocrine deficiency (1). In rare cases, non-islet cell tumor hypoglycemia (NICTH) is possible $(2,3)$. The underlying mechanism of NITCH is the overproduction of insulin-like growth factor (IGF) II by tumors. Hepatomas, fibromas, and fibrosarcomas are the most common of the many types of NICT. Phyllodes tumor of the breast is a rare fibroepithelial tumor with an average annual age-adjusted incidence rate of 2.1 per million in women. The incidence in Hispanic white women is higher than that in non-Hispanic white, Asian, and African American women (4). Phyllodes tumors are histologically classified as benign, borderline, or malignant; approximately $12-18 \%$ are borderline (5-7). There have been few reports of borderline phyllodes tumors with NICTH due to the secretion of high-molecular-weight IGF-II.
We herein present a case of a giant borderline phyllodes tumor of the breast with NICTH. Immunohistochemistry and Western blotting confirmed the secretion of high-molecularweight IGF-II by the tumor.

\section{Case Report}

A 50-year-old woman with a 1-year history of a large right breast mass was emergently admitted to our hospital with generalized weakness and fatigue. She had noticed the mass in her right breast 1 year previous and it had grown rapidly in the previous 6 months. During the same 6-month period, she also experienced weight loss. She had no significant medical or family history. A physical examination revealed normal findings, with the exception of a body mass index of $15.6 \mathrm{~kg} / \mathrm{m}^{2}$ and a large $(24 \times 16 \mathrm{~cm}$ in diameter) hemorrhagic lump with ulceration of the overlying skin in the right breast (Fig. 1A and B). The laboratory findings were as follows: hemoglobin, $8.9 \mathrm{~g} / \mathrm{dL}$; albumin, $1.8 \mathrm{mg} / \mathrm{dL}$;

\footnotetext{
${ }^{1}$ Department of Breast Surgery, Fujita Health University School of Medicine, Japan, ${ }^{2}$ Department of Diagnostic Pathology, Fujita Health University School of Medicine, Japan and ${ }^{3}$ Department of Biochemistry, Fujita Health University School of Medicine, Japan Received: April 1, 2017; Accepted: May 15, 2017; Advance Publication by J-STAGE: October 11, 2017 Correspondence to Dr. Toshiaki Utsumi, tutsumi@fujita-hu.ac.jp
} 
A

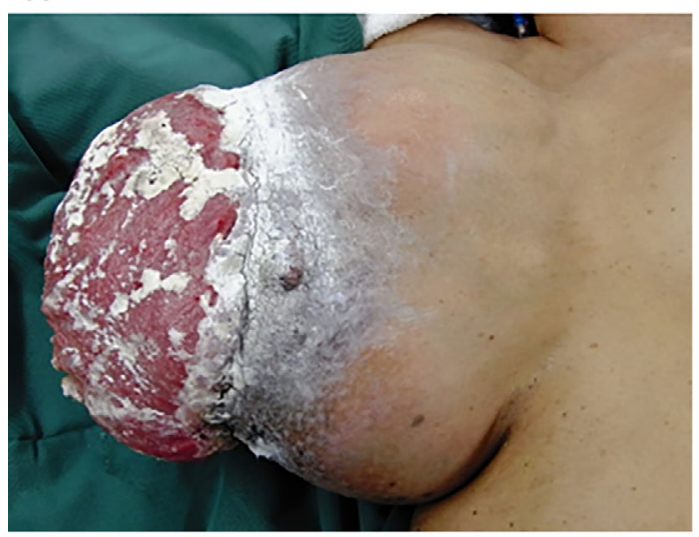

B

c

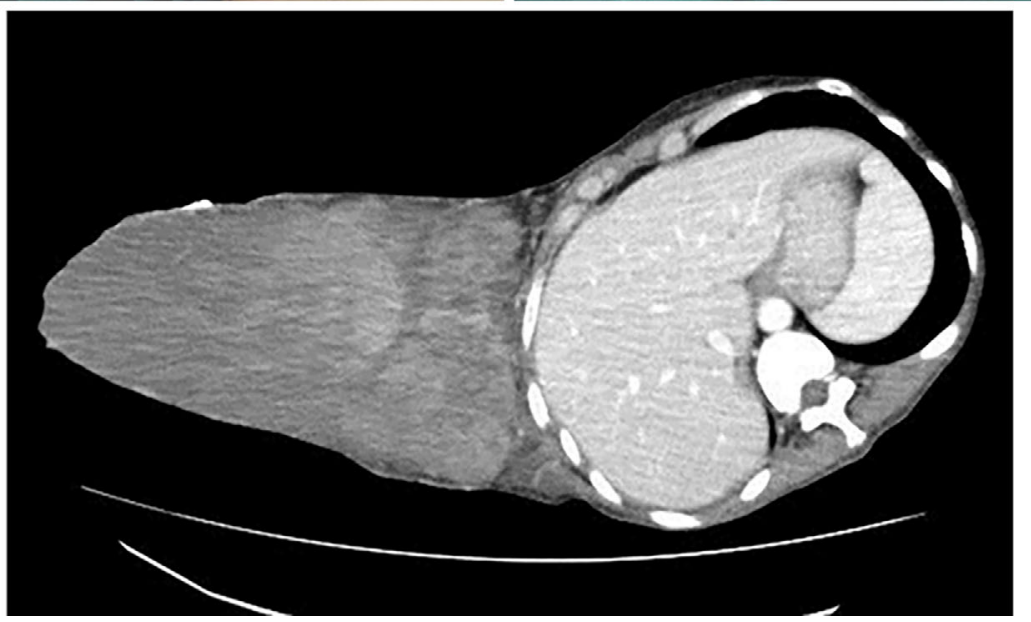

Figure 1. (A and B) The physical findings. A giant right breast mass measuring $24 \times 16 \mathrm{~cm}$ in diameter with ulceration of the overlying skin was observed. (C) Computed tomography revealed a heterogeneous giant mass in the right breast with ulceration of the overlying skin. No chest wall infiltration or axillary lymph node metastasis was observed.

Table. Laboratory Values before Surgery.

\begin{tabular}{lcc}
\hline & \multicolumn{1}{c}{ Value } & (Reference range) \\
\hline ACTH & $<1.6 \mathrm{pg} / \mathrm{mL}$ & $(7.2-63.3)$ \\
TSH & $0.55 \mu \mathrm{U} / \mathrm{mL}$ & $(0.35-4.94)$ \\
GH & $0.92 \mathrm{ng} / \mathrm{mL}$ & $(0-8.0)$ \\
PRL & $134.7 \mathrm{ng} / \mathrm{mL}$ & $(5.2-26.5)$ \\
Cortisol & $17.38 \mu \mathrm{g} / \mathrm{dL}$ & $(7.07-19.6)$ \\
Free T3 & $1.75 \mathrm{pg} / \mathrm{mL}$ & $(1.71-3.71)$ \\
Free T4 & $0.57 \mathrm{pg} / \mathrm{dL}$ & $(0.70-1.48)$ \\
C-peptide & $0.1 \mathrm{ng} / \mathrm{mL}$ & $(0.67-2.48)$ \\
Insulin & $<1.0 \mu \mathrm{U} / \mathrm{mL}$ & $(5.0-10.0)$ \\
Blood glucose & $61 \mathrm{mg} / \mathrm{dL}$ & $(70-109)$ \\
\hline
\end{tabular}

ACTH: adrenocorticotropic hormone, TSH: thyroid stimulating hormone, GH: growth hormone, PRL: prolactin, T3: Triiodothyronine, T4: Thyroxine

and blood glucose, $87 \mathrm{mg} / \mathrm{dL}$. The results of routine liver and renal function tests results were all normal. Thoracoabdominal computed tomography demonstrated a giant solid tumor in the right breast with ulceration of the overlying skin (Fig. 1C). A core biopsy of the tumor was performed, and a histological diagnosis of phyllodes tumor was made.
At dawn before breakfast on hospital day 22, the patient lost consciousness and was found to have severe hypoglycemia (blood glucose: $14 \mathrm{mg} / \mathrm{dL}$ ). After the intravenous injection of $50 \%$ glucose solution $(40 \mathrm{~mL})$ followed by intravenous hyperalimentation containing glucose (500 g/day), a blood sample was obtained for hormone measurement, after which hydrocortisone sodium succinate (200 mg/day) was administered. Thereafter, her blood glucose levels were controlled in the range of $80-200 \mathrm{mg} / \mathrm{dL}$. Hypopituitarism and hypothyroidism were excluded based on the laboratory examination results; her plasma C-peptide $(0.1 \mathrm{ng} / \mathrm{mL})$ and insulin $(<1 \mu \mathrm{IU} / \mathrm{mL})$ levels were suppressed, while her blood glucose level was $61 \mathrm{mg} / \mathrm{dL}$ (Table). Anti-insulin antibody testing was negative. Given the biochemical and histological findings, phyllodes tumor-associated NICTH was suspected. On hospital day 24, the patient underwent right mastectomy. The tumor was $27 \times 23 \times 23 \mathrm{~cm}$ in size, weighed $4,456 \mathrm{~g}$, had clearly defined borders, and was soft and pliable. The gross examination of the cut surface of the solid tumor revealed it was milky-white with some degenerative changes and bleeding. The resected tumor was diagnosed as a borderline phyllodes tumor based on the results of a histopathological examination (Fig. 2A and B). After surgery, the patient's blood 

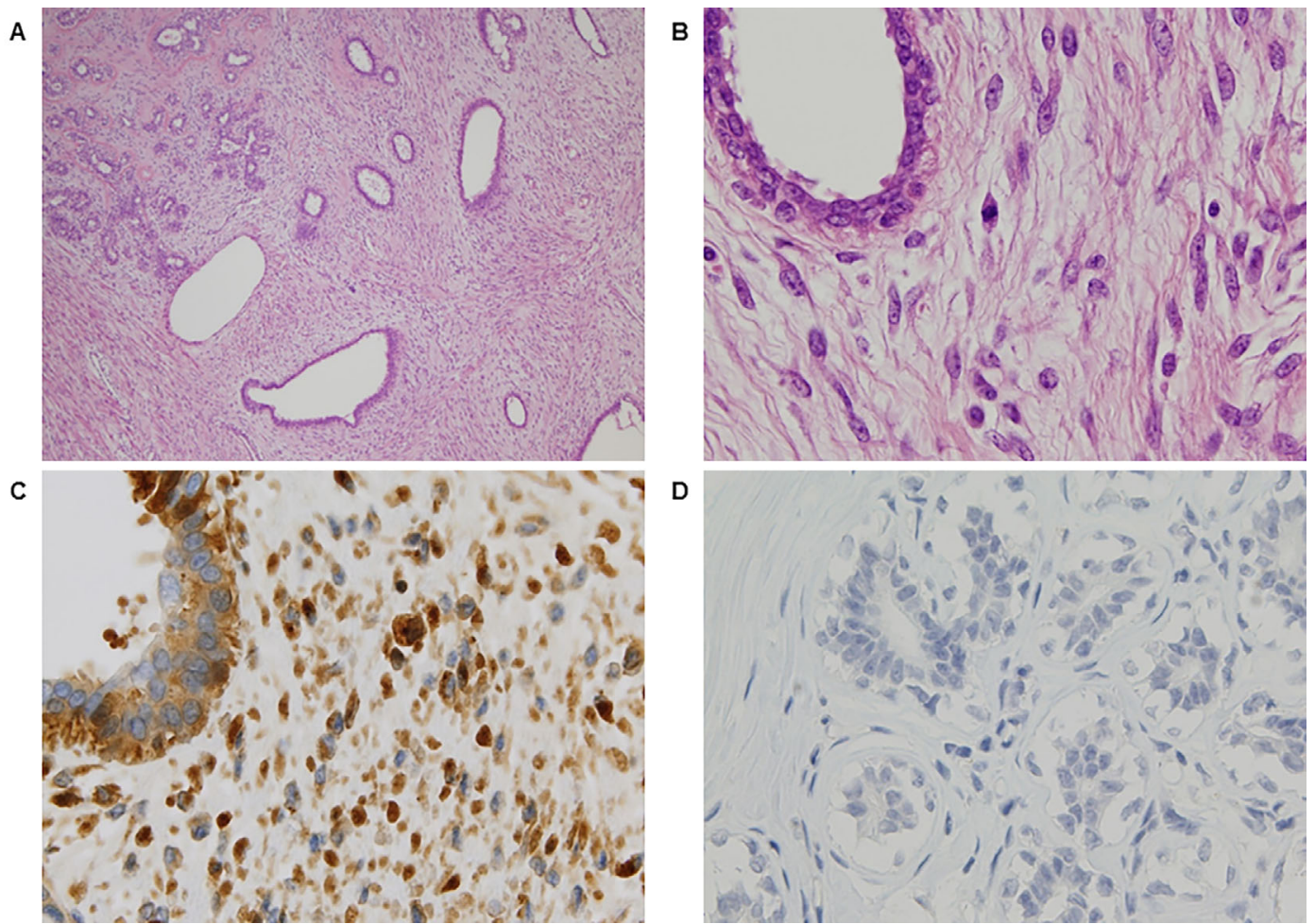

Figure 2. The microscopic findings [Hematoxylin and Eosin (H\&E) staining and immunohistochemical staining of the resected tumor]. H\&E staining (A) Low-power $(\times 40)$ and $(B)$ high-power $(\times 400)$ views showed moderate stromal hypercellularity with mild nuclear atypia and mild pleomorphism of the spindle cells. Focal mildly atypical epithelial hyperplasia was also noted. Stromal overgrowth was absent. Immunohistochemical staining of (C) the phyllodes tumor and (D) normal breast tissue using rabbit polyclonal anti-insulin-like growth factor II (IGF-II) antibodies. The tumor cells, but not the normal breast tissue, were diffusely immunopositive for IGF-II.

$\operatorname{Mr}(\mathrm{KDa})$

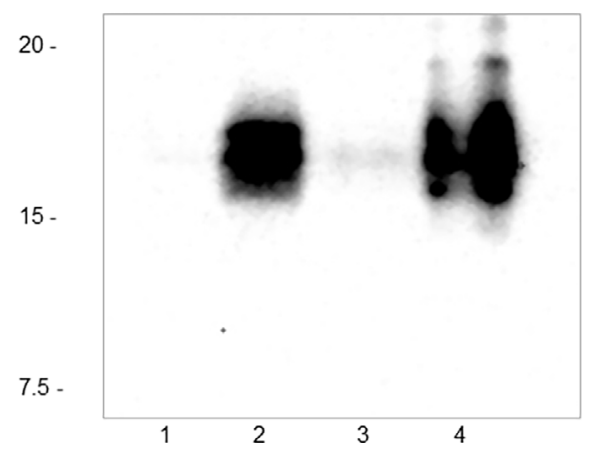

Figure 3. Western blotting of high-molecular-weight IGF-II. Lane 1, serum from a healthy control; lane 2, serum from the patient collected preoperatively; lane 3 , serum obtained 3 days after the resection of the tumor; lane 4 , phyllodes tumor tissue. Large amounts of high-molecular-weight IGF-II were detected in the serum collected preoperatively (lane 2 ) and in the tumor tissue (lane 4) but not in serum collected postoperatively (lane 3) or a serum sample from a healthy control (lane 1).

glucose levels quickly normalized, and the patient made a complete recovery from the episode of hypoglycemia. In three years of follow-up, there has been no recurrence of the tumor.
The patient's serum levels of IGF-II before and 3 days after surgery and tumor tissue were measured by Western blotting, as described briefly below. Serum samples were diluted to $1 \mu \mathrm{g} / \mu \mathrm{L}$ protein using ice-cold phosphate-buffered saline [PBS: $10 \mathrm{mM}$ sodium phosphate buffer $(\mathrm{pH}$ 7.4) containing $0.15 \mathrm{M} \mathrm{NaCl}$. The tissue sample was homogenized in icecold PBS by a Potter type homogenizer and centrifuged at $500 \times g$ for 5 minutes at $4^{\circ} \mathrm{C}$. The supernatant was collected and diluted to $1 \mu \mathrm{g} / \mu \mathrm{L}$ protein using ice-cold PBS. The total protein concentration was determined using Quick Start ${ }^{\mathrm{TM}}$ Bradford Protein Assay Kits (Bio-Rad Laboratories, Hercules, USA). After adding $5 \times$ sodium dodecyl sulfate sample buffer to each of the samples, equal amounts $(1 \mu \mathrm{g})$ of proteins from the serum and the phyllodes tumor were used for the analysis. Protein extracts were separated by $15 \%$ sodium dodecyl sulfate-polyacrylamide gel electrophoresis and transferred onto a polyvinylidene difluoride membrane (GE Healthcare, Chicago, USA). They were probed with rabbit polyclonal anti-IGF-II antibody (Atlas Antibodies, Bromma, Sweden). The proteins of interest were detected with a horseradish peroxidase (HRP)-labeled secondary anti-rabbit IgG antibody (Bio-Rad Laboratories, Hercules, USA) and visualized with Immobilon Western Chemiluminescent HRP Substrate (Millipore, Billerica, USA).

As shown in Fig. 3, large amounts of high-molecular- 
weight IGF-II were detected in the serum that was collected preoperatively and in the tumor tissue, but not in the serum that was collected postoperatively. Furthermore, immunohistochemical staining for IGF-II revealed numerous immunopositive tumor cells (Fig. 2C and D).

\section{Discussion}

Tumor-associated hypoglycemia can be classified into two categories according to the mechanism underlying its development. Hypoglycemia due to the hypersecretion of insulin from insulinomas is the most common mechanism. The second mechanism, known as NICTH, involves the paraneoplastic production of high-molecular-weight IGF-II by a tumor. This leads to hypoglycemia via abnormal IGF-II binding to tissue insulin receptors. In 1988, Daughaday et al. reported the first case of high-molecular-weight IGF-II produced by a leiomyosarcoma in a patient with NICTH (8). Although the true incidence of NICTH is unclear, it is estimated to be extremely rare at 1 per million person-years (2). A population-based study revealed that the age-adjusted annual incidence of phyllodes tumor was 2.1 per million women (3). Phyllodes tumor is histologically classified into the benign, borderline, and malignant types, with $58-64 \%$ classified as benign tumors, $12-18 \%$ classified as borderline tumors, and $18-30 \%$ classified as malignant tumors (4-6). Taking these findings into consideration, borderline phyllodes tumor accompanied by NICTH is extremely rare. A search of the PubMed database for studies published up to March 2017 using the terms "hypoglycemia" and "phyllodes tumor," yielded ten reports describing phyllodes tumors with NICTH, with only one case of a borderline phyllodes tumor (9).

The cause of NICTH is the overproduction of incompletely processed IGF-II; this high-molecular-weight IGF-II stimulates insulin receptors and increases glucose utilization. This form of IGF-II is in an 11-18 $\mathrm{kDa}$ fraction of the tumor. High-molecular-weight or immature IGF-II has higher bioactivity than mature IGF-II (a $7.5 \mathrm{kDa}$ fraction) (3). Mature IGF-II is usually found in the circulation bound to IGFbinding protein 3 (IGFBP-3). In general, $70-80 \%$ of IGF-II is in an inactive form when it is part of a ternary $150-\mathrm{kDa}$ complex with IGFBP-3 and acid-labile subunit (3). Moreover, in comparison to mature IGF-II, high-molecular-weight IGF-II has a lower affinity for IGFBP-3; as a consequence, its bioavailability is increased, which causes hypoglycemia (3).

In this case, Western blotting clearly showed large amounts of high-molecular-weight IGF-II in serum that was collected preoperatively and in the tumor tissue, but not in serum that was obtained 3 days after tumor resection. Moreover, immunohistochemistry demonstrated that the tumor cells were positive for anti-IGF-II antibodies. Although the anti-IGF-II antibody used in this study is not specific for high-molecular-weight IGF-II proteins, the development of hypoglycemia suggests that it was associated with the IGF-II secreted from the tumor cells. Indeed, the high-molecularweight IGF-II disappeared and the patient's blood glucose levels normalized after the resection of the tumor. Ultimately, the patient made a complete recovery from the hypoglycemic episode.

Our study is associated with some limitations. We did not measure the serum IGF-II concentrations. However, our study also contains several strengths. We measured the highmolecular-weight IGF-II in the patient's serum and tumor tissue by Western blotting. We also performed an immunohistochemical analysis to search for IGF-II in the tumor tissue. In a previous study of borderline phyllodes tumors, both analyses were not available.

It is currently recognized that a wide variety of tumor types have the potential to produce IGF-II; however, mesenchymal and hepatic tumors are reported to be the types that are most commonly associated with NICTH (2). This patient had a large phyllodes tumor, a type of fibroepithelial neoplasm. NICTH should be considered when hypoglycemia without hyperinsulinemia occurs in the context of a large phyllodes tumor of the breast. In the acute management of hypoglycemia, the immediate correction of hypoglycemia is very important. Once the diagnosis of NICTH is made, the most effective treatment is the complete resection of the IGF-II-producing tumor (10). Indeed, in our patient, the resection of the tumor was a very effective treatment for NICTH.

In conclusion, we herein described a rare case of NICTH due to high-molecular-weight IGF-II in a patient with a giant borderline phyllodes tumor. This is the first report of the presence of IGF-II in a borderline phyllodes tumor based on Western blotting and immunohistochemistry.

The authors state that they have no Conflict of Interest (COI).

\section{References}

1. Güven M, Bayram F, Güven K, Kelestimur F. Evaluation of patients admitted with hypoglycaemia to a teaching hospital in Central Anatolia. Postgrad Med J 76: 150-152, 2000.

2. Marks V, Teale JD. Tumours producing hypoglycaemia. Diabetes Metab Rev 7: 79-91, 1991.

3. Dynkevich Y, Rother KI, Whitford I, et al. Tumors, IGF-2, and hypoglycemia: insights from the clinic, the laboratory, and the historical archive. Endocr Rev 34: 798-826, 2013.

4. Bernstein L, Deapen D, Ross RK. The descriptive epidemiology of malignant cystosarcoma phyllodes tumors of the breast. Cancer 71: 3020-3024, 1993.

5. Chaney AW, Pollack A, McNeese MD, et al. Primary treatment of cystosarcoma phyllodes of the breast. Cancer 89: 1502-1511, 2000 .

6. Ben Hassouna J, Damak T, Gamoudi A, et al. Phyllodes tumors of the breast: a case series of 106 patients. Am J Surg 192: 141-147, 2006.

7. Belkacémi Y, Bousquet G, Marsiglia H, et al. Phyllodes tumor of the breast. Int J Radiat Oncol Biol Phys 70: 492-500, 2008.

8. Daughaday WH, Emanuele MA, Brooks MH, Barbato AL, Kapadia M, Rotwein P. Synthesis and secretion of insulin-like growth factor II by a leiomyosarcoma with associated hypoglyce- 
mia. N Engl J Med 319: 1434-1440, 1998.

9. Saito Y, Suzuki Y, Inomoto C, et al. A case of giant borderline phyllodes tumor of the breast associated with hypoglycemia. Tokai J Exp Clin Med 41: 118-122, 2016.

10. Bodnar TW, Acevedo MJ, Pietropaolo M. Management of nonislet-cell tumor hypoglycemia: a clinical review. J Clin Endocrinol
Metab 99: 713-722, 2014.

The Internal Medicine is an Open Access article distributed under the Creative Commons Attribution-NonCommercial-NoDerivatives 4.0 International License. To view the details of this license, please visit (https://creativecommons.org/licenses/ by-nc-nd/4.0/).

(C) 2018 The Japanese Society of Internal Medicine

Intern Med 57: 237-241, 2018 